\title{
Rejestr popisowy chorągwi pospolitego ruszenia powiatu kaliskiego pułkownika Jakuba Rozdrażewskiego w 1651 roku
}

ZARYS TREŚcI: Niniejsza edycja źródłowa prezentuje rejestr popisowy jednej chorągwi pospolitego ruszenia powiatu kaliskiego, która została zorganizowana i wysłana pod Beresteczko, z zamiarem wzięcia udziału w bitwie przeciwko siłom kozacko-tatarskim. Była to jedna z trzech grup, które zostały utworzone w powiecie kaliskim przez kasztelana kaliskiego Jakuba Rozdrażewskiego. Chorągiew liczyła 109 pospolitaków, którymi dowodził w zastępstwie kasztelana kaliskiego porucznik Władysław Gądkowski.

SŁOWA KLUCzowE: rejestr, popis, pospolite ruszenie, pułkownik, porucznik, pospolitacy

ABSTRACT:

This source edition shows the register of one mass levy company from the Kalisz poviat, which was formed and sent to Beresteczko in order to take part in the battle against Cossack-Tatar forces. It was one of three groups assembled in the Kalisz poviat by the castellan of Kalisz Jakub Rozdrażewski. The company numbered 109 mass levy troops commanded by Lieutenant Władysław Gądkowski in place of the castellan of Kalisz.

KEYWORDS: signature register of mass levy, muster of mass levy, levy in mass, colonel, lieutenant, mass levy members 
Pospolite ruszenie było jedną z najstarszych formacji zbrojnych w polskim systemie wojskowym okresu przedrozbiorowego. Jego początków należałoby upatrywać $\mathrm{w}$ okresie średniowiecza, kiedy to każdy posiadacz ziemski zobowiązany był do służby wojskowej. Pospolite ruszenie w polskim systemie wojskowym przetrwało aż do końca XVII w. Później, mimo iż istniała możliwość jego zwoływania, nie korzystano z niej. Na przestrzeni lat zmieniła się rola pospolitego ruszenia w systemie wojskowym. W średniowieczu stanowiło ono podstawę sił zbrojnych, a w okresie nowożytnym traktowano je jako ostatnią linię obrony kraju, co najtrafniej określił Piotr Opaliński na sejmiku w Środzie w 1624 r., mówiąc: „na gwałt raczy ostatni to violentum remedium zachowujmy"1.

Organizacja wypraw pospolitego ruszenia wiązała się z szeregiem procedur organizacyjnych, nad którymi czuwali najwyżsi urzędnicy w postaci starostów generalnych, wojewodów i kasztelanów. Na początku procesu organizacyjnego, zgodnie z zapisami artykułów henrykowskich sejm musiał wyrazić zgodę na organizację wyprawy. Następnie król wysyłał wici na pospolite ruszenie, w których kluczowy był terminarz stawienia się do punktu zbornego. W tym momencie kończył się udział państwa, a zaczynała działalność samorządu szlacheckiego. Przygotowanie wyprawy zatwierdzano na sejmiku ziemskim, po czym wojewoda lub starosta generalny wydawał uniwersał, w którym wzywał szlachtę na popisy w powiatach pod nadzorem kasztelanów. Następnie brać szlachecka zjeżdżała się na ustalone miejsce, gdzie dokonywano popisu, podczas którego przeliczano obecnych posesorów ziemskich i sprawdzano stan ich uzbrojenia. W dalszej kolejności kasztelan prowadził szlachtę na popis wojewódzki, by przekazać swoich ludzi wojewodzie, który następnie prowadził całe województwo do miejsca koncentracji².

$\mathrm{W}$ trakcie całej procedury organizacyjnej powstawało wiele dokumentów, które były oblatowane w księgach grodzkich i ziemskich, by nadać im odpowiedni status prawny. Jednym z najważniejszych dokumentów były rejestry popisowe, pokazujące rzeczywistą liczebność oddziałów pospolitego ruszenia oraz dające nam pewien obraz szlacheckich popisów. Dla historyków rejestry te są nieocenionym źródłem wiedzy, szczególnie przydatnym w badaniach dawnej wojskowości,

${ }^{1}$ Mowa Piotra Opalińskiego, wojewody poznańskiego, na sejmiku przedsejmowym województw poznańskiego i kaliskiego w Środzie 9-13 I 1624 r., [w:] Akta sejmikowe województw poznańskiego i kaliskiego, oprac. W. Dworzaczek, t. 1 (1572-1632), cz. 2(1617-1632), Poznań 1962, s. 160-162; D. Kupisz, Wyprawy żołnierza łanowego w Koronie w czasach Jana Kazimierza, Warszawa 2018, s. 35.

2 K. Hahn, Pospolite ruszenie wedle uchwat sejmikowych ruskich od XVI do XVIII wieku,,Pamiętnik Historyczno-Prawny", t. 6, 1928, cz. 4, s. 4-16; J. Majchrowski, Wojewoda w dawnej Polsce, Warszawa 2019, s. 82. 
społeczeństwa szlacheckiego czy też genealogii i prozopografii. Dzięki pracy edytorskiej historyków epoki nowożytnej, do tej pory ukazało się wiele edycji źródłowych rejestrów popisowych. Można wymienić chociażby te autorstwa: Henryka Gmiterka, Artura Goszczyńskiego, Roberta Kozyrskiego, Dariusza Kupisza, Józefa Kusa, Sławomira Leitgebera, Jacka Pielasa, Bartosza Staręgowskiego, Zofii Trawickiej czy Leszka Wierzbickiego ${ }^{3}$. Andrzej Rachuba oraz Jacek Pielas opracowali również w formie książkowej rejestry popisowe Wielkiego Księstwa Litewskiego oraz województwa sandomierskiego ${ }^{4}$. Rejestry popisowe są też istotnym elementem edycji źródłowych akt sejmikowych ${ }^{5}$.

Rok 1651 to kolejna odsłona zmagań w ramach wojny domowej z wojskiem zaporoskim. Walki z lat 1648-1649 obfitowały w wiele wydarzeń natury wojskowej, często bardzo niekorzystnych dla wojska polskiego. W $1650 \mathrm{r}$. nastąpiło

3 H. Gmiterek, Rejestry szlachty ziemi chetmskiej z lat 1669-1672, „Rocznik Chełmski”, t. 2, 1996, s. 327-339; A. Goszczyński, „Szlachty przemyskiej kwiat zgubiony”. Regestr pospolitego ruszenia powiatu przemyskiego pod regimentem skarbnika lwowskiego Zygmunta Przedwojewskiego, [w:] Studia nad staropolską sztuką wojenną, t. 4, red. Z. Hundert, J. J. Sowa, K. Żojdź, Oświęcim 2015, S. 259-275; R. Kozyrski, Popisy (okazowania) szlachty w Rzeczypospolitej w II połowie XVII wieku. Popis Chetmian z 7 sierpnia 1649 roku, „Rocznik Chełmski”, t. 7, 2001, s. 341-358; Popis szlachty ziemi stężyckiej z 1696 roku, wyd. D. Kupisz, „Res Historica”, t. 17, 2004, s. 171-176; Okazowania szlachty stężyckiej z lat 1648-1649, wyd. D. Kupisz, „Res Historica”, t. 24, 2007, s. 161-169; Popis pospolitego ruszenia szlachty województwa lubelskiego z 1649 roku, wyd. J. Kus, „Region Lubelski”, nr 6 (8), 1994-1996, s. 133-142; S. Leitgeber, Spis szlachty powiatu kcyńskiego z 1621 roku, „Genealogia”, t. 5, 1995, s. 141-144; Rejestr pospolitego ruszenia powiatu sandomierskiego $z 1621$ r., wyd. J. Pielas, „Studia i Materiały do Historii Wojskowości”, t. 41, 2004, s. 141-169; Rejestr pospolitego ruszenia księstw oświęcimskiego i zatorskiego z 18 października 1621 roku, wyd. J. Pielas, „Res Historica”, t. 42, 2016, s. 353-377; B. Staręgowski, Rejestr pospolitego ruszenia powiatu poznańskiego $z 28$ sierpnia 1649 r., „Przegląd Historyczno-Wojskowy”, nr 4 (258), 2016, s. 141-151; Popis powiatu chęcińskiego z 1621 roku, wyd. Z. Trawicka, „Kieleckie Studia Historyczne”, t. 4, 1985, s. 39-47; L. Wierzbicki, Rejestr pospolitego ruszenia województwa betskiego z 1669 r., „Rocznik Lubelski”, t. 42, 2016, s. 229-234.

${ }^{4}$ Rejestry popisowe szlachty Wielkiego Księstwa Litewskiego z 1621 r., oprac. A. Rachuba, Warszawa 2015; Źródła i materiały do dziejów szlachty województwa sandomierskiego w XVI-XVIII wieku, t. 1: Rejestry pospolitego ruszenia szlachty sandomierskiej z XVII wieku, oprac. J. Pielas, Kielce 2009.

5 Wymienić tu należy m.in. Akta sejmikowe województw poznańskiego i kaliskiego. Lata 1668-1675, oprac. M. Zwierzykowski, R. Kołodziej, A. Kamieński, Poznań 2018;Akta sejmikowe województw poznańskiego i kaliskiego. Lata 1676-1695, oprac. M. Zwierzykowski, R. Kołodziej, A. Kamieński, Poznań 2019; Akta sejmikowe województw poznańskiego i kaliskiego. Lata 1696-1732, oprac. M. Zwierzykowski, Poznań 2008; Akta sejmikowe województwa bełskiego. Lata 1572-1655, oprac. M. Zwierzykowski, R. Kołodziej, Poznań 2008; Akta sejmikowe województwa lubelskiego 1572-1632, oprac. H. Gmiterek, Lublin 2016; Akta sejmikowe Ziemi Chetmskiej 1572-1668, oprac. W. Bondyra, H. Gmiterek, J. Ternes, Lublin 2013. 
chwilowe uspokojenie sytuacji, a dla armii koronnej moment przegrupowania i gromadzenia sił. Na grudniowej sesji sejmu walnego w 1650 r. szlachta zgodziła się na organizację ogólnopolskiej wyprawy, która miała zostać przeprowadzona wedle założeń konstytucji z $1621 \mathrm{r}^{6}{ }^{6}$ Po zakończeniu sejmu do szlachty województw poznańskiego i kaliskiego trafiły uniwersały królewskie, które wzywały ją do mobilizacji, organizacji lokalnych popisów oraz przybycia do określonego miejsca koncentracji, na które początkowo wyznaczono Konstantynów. Termin ustalono na dzień 5 czerwca $1651 \mathrm{r}$. Na popisie generalnym obu województw Wielkopolanie stanąć mieli 9 maja ${ }^{7}$.

Szlachta wielkopolska zebrana na sejmiku obu województw w Środzie 9 maja 1651 r., zwołanym na mocy uniwersału Jana Kazimierza trzecich wici, zatwierdziła postanowienia konstytucji grudniowego sejmu odnośnie do organizacji wyprawy pospolitego ruszenia i nakazała przeprowadzanie popisów powiatowych. Miały one odbyć się w maju pod stolicami poszczególnych powiatów, a następnie zebrani pospolitacy powinni udać się do miejsca wyznaczonego w uniwersałach królewskich. Zrezygnowano z popisów wojewódzkich, co było podyktowane koniecznością szybkich działań mobilizacyjnych. Opóźnienia wynikały w głównej mierze z późnego wydania trzecich wici' ${ }^{9}$ Niedługo po rozpoczęciu formowania wyprawy Jan Kazimierz przysłał informację o zmianie miejsca koncentracji, spowodowanej zajęciem Konstantynowa przez Kozaków. Nowe miejsce miało być podane możliwie jak najszybciej ${ }^{10}$. Kilka dni później, 14 maja, Jan Kazimierz dotarł pod Sokal i z tego miejsca rozpoczął rozsyłanie nowych wici. Obóz pod Sokalem stał się nowym miejscem

${ }^{6}$ Volumina Constitutionum, t. 4 (1641-1668), vol. 1 (1641-1658), red. S. Grodziski, M. Kwiecień, K. Fokt, Warszawa 2015, s. 225, 227-229, 232; S. Ochmann-Staniszewska, Sejm Rzeczypospolitej za panowania Jana Kazimierza Wazy. Prawo-doktryna-praktyka, t. 1, Wrocław 200o, s. $74-88$.

7 Uniwersał JKM do szlachty województw poznańskiego i kaliskiego, Warszawa 5 I 1651, uniwersał JKM do szlachty województw poznańskiego i kaliskiego, Warszawa 4 III 1651, Archiwum Państwowe w Poznaniu (dalej: APPoz.), księgi grodzkie poznańskie (dalej: Gr. Pozn.), relacje, sygn. 696, k. 22-22V, 203-203V; uniwersał JKM do szlachty województw poznańskiego i kaliskiego, Lublin 20 IV 1651, APPoz., księgi grodzkie wałeckie, relacje, sygn. 28, k. 72V-74v.

8 Uniwersał JKM do szlachty województw poznańskiego i kaliskiego, Lublin 20 IV 1651, APPoz., Gr. Pozn., 696, k. 317-319.

9 Laudum średzkie, Środa 12 V 1651, ibidem, k. 334V-336.

10 Uniwersał JKM do szlachty województw poznańskiego i kaliskiego, Uchanie $12 \mathrm{~V} 1651$, ibidem, k. 353-354. 
koncentracji, pod które docierały wojska koronne. Dopiero 15 czerwca ruszono pod Beresteczko ${ }^{11}$.

Problem z ustaleniem miejsca był jednym z nielicznych błędów wyprawy w 1651 r. Pomimo tego jest ona uważana za jedną z najlepiej przygotowanych wypraw w historii pospolitego ruszenia, o czym przekonuje nas L. Wierzbicki ${ }^{12}$. Trudno się z tym nie zgodzić. Również Wielkopolska, będąca prowincją oddaloną od głównego teatru działań zbrojnych, nad wyraz energicznie przystąpiła do formowania wyprawy. W województwie kaliskim o właściwy przebieg organizacyjny zadbał kasztelan kaliski Jakub Hieronim Rozdrażewski, który przejął obowiązki wojewody kaliskiego Andrzeja Karola Grudzińskiego, którego z kolei zatrzymały absorbujące obowiązki na dworze królewskim. Decyzja o takim podziale obowiązków zapadła na sejmiku zorganizowanym przy okazji pospolitego ruszenia w dniach $23-26$ maja $1651 \mathrm{r}^{13}$

Rozdrażewski od 1649 r. pełnił obowiązki kasztelana kaliskiego ${ }^{14}$, i trzeba przyznać, że w charakterystyczny sposób organizował wyprawę. Podległy sobie powiat kaliski dzielił zazwyczaj na trzy grupy, czego dokonał już w 1649 r., choć wówczas wyprawa nie doszła do skutku ${ }^{15}$.Również tym razem zrobił podobnie. Pospolitacy z powiatu kaliskiego zostali podzieleni na trzy chorągwie, dowodzone przez porucznika Władysława Gądkowskiego i rotmistrzów Andrzeja Przyjemskiego oraz Wojciecha Szołdrskiego ${ }^{16}$. Sam Rozdrażewski postanowił dołączyć do chorągwi porucznika Władysława Gądkowskiego, która jest przedmiotem niniejszej edycji źródłowej. Te trzy grupy miały maszerować gościńcem oddzielnie. Dopiero w momencie przeprawiania się przez Wisłę miało dojść do

${ }^{11}$ M. Nagielski, Pospolite ruszenie szlachty w świetle kampanii zborowskiej i beresteckiej przeciwko Kozakom (1649-1651),[w:] Studia Historyczno-Wojskowe, red. T. Ciesielski, t. 3, 2009, S. 102-104.

12 L. Wierzbicki, Pospolite ruszenie w Polsce w drugiej połowie XVII wieku. Ostatnie wyprawy $z$ lat 1670-1672, Lublin 2011, s. 26, 28.

${ }^{13}$ Laudum powiatu kaliskiego pod Kaliszem na pospolite ruszenie idącym, Kalisz 26 V 1651, APPoz., Gr. Kal., 276, k. 214-216.

${ }^{14}$ W. Kłaczewski, Rozdrażewski Jakub Hieronim, [w:] Polski Słownik Biograficzny, t. 32, Wrocław- Warszawa- Kraków 1989-1991, s. 369.

15 Laudum powiatu kaliskiego pod Kaliszem na pospolite ruszenie idącym, Kalisz 30 VIII 1649, APPoz., księgi grodzkie kaliskie (dalej: Gr. Kal.), relacje, 274, k. 578v-579v.

16 Laudum powiatu kaliskiego pod Kaliszem na pospolite ruszenie idącym, Kalisz 26 V 1651, APPoz., Gr. Kal., 276, k. 214V-216; Rejestr popisu pospolitego ruszenia powiatu kaliskiego Andrzeja Przyjemskiego, APPoz., Gr. Kal., 277, k. 45v-46v. 
połączenia ich w jedno zgrupowanie, tak żeby do Lublina dotarł cały powiat kaliski. W ramach poprawy dyscypliny kasztelan zakazał postojów we wsiach i w miasteczkach, a pozwolił jedynie na obozowanie w otwartym polu. Aby ograniczyć nadużycia przy wybieraniu towarów aprowizacyjnych, Rozdrażewski nakazał sporządzanie dokumentów sprzedaży danego towaru w obecności dwóch świadków. W pozostałych powiatach województwa kaliskiego popisy odbywały się pod kasztelanami bez zakłóceń. W tych przypadkach również nie obyło się bez dzielenia grup powiatowych na mniejsze jednostki taktyczne ${ }^{17}$.

Wielkopolanie musieli przebyć szmat drogi, która dzieliła Wielkopolskę od Wołynia. Marsz dodatkowo opóźniały wydarzenia natury losowej i niezdyscyplinowanie pospolitaków. Najszybciej do obozu pod Sokalem dotarły województwa bełskie i wołyńskie oraz ziemia chełmska. Następnie przybyły województwa: lubelskie, podlaskie, krakowskie, sandomierskie, łęczyckie, sieradzkie i ziemia sanocka. Najpóźniej dotarły województwa wielkopolskie i mazowieckie $^{18}$. Jeszcze $\mathrm{w}$ trakcie przemarszu wielkopolskie chorągwie pospolitego ruszenia zatrzymały się w Lublinie, gdzie zarządzono postój w celu aprowiza$\mathrm{cji}^{19}$. To tutaj najprawdopodobniej popisała się chorągiew Rozdrażewskiego, a następnie rejestr popisowy trafił do ksiąg grodzkich lubelskich. Tak czy inaczej pospolite ruszenie z województwa kaliskiego dotarło do obozu 5 lipca, czyli już po samej bitwie. Hasłem dla Kaliszan był „św. Florian”20 . Z uwagi na to, że bitwa dobiegła końca, przydzielono kaliskich pospolitaków do straży obozowej $^{21}$. Na marginesie trzeba dodać, że nie były to jedyne siły podległe Rozdrażewskiemu. Najpierw w obozie pod Sokalem znalazła się, a następnie brała udział w bitwie pod Beresteczkiem 100-konna prywatna chorągiew husarska kasztelana kaliskiego ${ }^{22}$.

17 Rejestr popisu pospolitego ruszenia powiatu kcyńskiego Adama Baranowskiego, Kcynia 23 V 1651, APPoz., księgi grodzkie kcyńskie, relacje, 86, s. 1876-1879; Atestacja szlachty powiatu nakielskiego, Nakło 23 V 1651, APPoz., księgi grodzkie nakielskie, relacje, 117, k. 435-436.

${ }_{18}$ M. Nagielski, op. cit., s. 102-107.

19 Protestacja Macieja Wilczyckiego, APPoz., Gr. Kal., 276, k. 323v-324v.

${ }^{20}$ Diariusz wojny pod Beresteczkiem z chanem krymskim $i$ Kozakami zaporoskiemi za szcześliwego panowania Króla JM. Jana Kazimierza, na którą sam osobą swą ruszeł się z Warszawy In Anno 1651,[w:] Relacje wojenne z pierwszych lat walk polsko-kozackich powstania Bohdana Chmielnickiego okresu „Ogniem i Mieczem” (1648-1651),oprac. M. Nagielski, Warszawa 1999, s. 254.

21 S. Oświęcim, Diariusz Stanisława Oświęcima 1643-1651,[w:] Scriptores Rerum Polonicarum, t. 19, wyd. W. Czermak, Kraków 1907, s. 347.

${ }^{22}$ W. Kłaczewski, op. cit., s. 369. 
Rejestr pospolitego ruszenia, którego dotyczy niniejsza edycja źródłowa, został sporządzony najprawdopodobniej podczas postoju aprowizacyjnego pospolitego ruszenia pod Lublinem. Rejestr nie jest datowany, aczkolwiek zachował się uniwersał Jakuba Rozdrażewskiego z okresu stacjonowania pod Lublinem, który datowany jest na 20 czerwca $1651 \mathrm{r}^{23}$ Można domniemywać, że w tym czasie dokonano również popisu z uwagi na to, że uniwersał został oblatowany w księdze grodzkiej obok rejestru. Chorągiew liczyła 109 pospolitaków, a komendę nad nią oficjalnie sprawował sam pułkownik Jakub Rozdrażewski. W rzeczywistości dowodził nią porucznik Władysław Gądkowski. W chorągwi było obecnych również trzech urzędników wielkopolskich: podczaszy kaliski Wawrzyniec Przyborowski, pisarz grodzki gnieźnieński Krzysztof Twardowski oraz poborca kaliski Stanisław Dobrosielski.

Rejestr popisowy został oblatowany 21 czerwca 1651 r. w księdze grodzkiej lubelskiej, serii Relacje o sygnaturze $79^{24}$. Księga liczy 1030 kart. Edycję źródłową sporządzono według wytycznych Instrukcji wydawniczej dla źródeł historycznych od XVI do połowy XIX wieku pod redakcją Kazimierza Lepszego ${ }^{25}$.

\section{Tekst źródła}

Or.: Archiwum Państwowe w Lublinie, Księgi grodzkie lubelskie, Relacje, sygn. 79 , k. 492-493v.

[k. 492] Regestr towarzystwa wszystkiego per oblatam podany do ksiąg grodzkich lubel[skich] którzy na ten czas continue pod chorągwią byli i od niej się nie absentowali namiestnikiem natenczas będąc na miejscu Jaśnie Wielmożnego JM pana Jakuba Hieronima na Rozdrażewie Rozdrażewskiego kasztelana kaliskiego, konińskiego, kolskiego i starosty, Władysław

23 Uniwersał kasztelana kaliskiego Jakuba Rozdrażewskiego do szlachty województwa kaliskiego, Lublin 20 VI 1651, Archiwum Państwowe w Lublinie (dalej: APL), Księgi grodzkie lubelskie (Relacje) (dalej: KGL), sygn. 79, k. 491-491v.

24 Rejestr popisowy chorągwi pospolitego ruszenia powiatu kaliskiego pułkownika Jakuba Rozdrażewskiego, APL, KGL, 79, k. 492-493v, 494v.

${ }^{25}$ Instrukcja wydawnicza dla źródeł historycznych od XVI do połowy XIX wieku, red. K. Lepszy, Wrocław 1953. 
z Szczodrzykowa Gądkowski miecznik województwa kaliskiego natenczas porucznik tejże chorągwi.

JM pan pułkownik ${ }^{1}$, JM pan porucznik ${ }^{2}$, JM pan chorąży, JM ksiądz kapelan, muzyka wojskowa, JM pan podczaszy kaliski ${ }^{3}$, JM pan pisarz grodzki gnieźnieński ${ }^{4}$, JM pan Jan Lipski, JM pan Kazimierz [k. 492v] Mikołajewski, JM pan Andrzej Radoliński, JM pan Piotr Tomicki, JM pan Wojciech Jarochowski, JM pan Zaręba, JM pan Stefan Gądkowski, JM pan Laskowski, JM pan poborca kaliski ${ }^{5}$, JM pan Stanisław Zajączek, JM pan Olbrycht Zajączek, JM pan Marc[jan] Lisiecki, JM pan Andrzej Zawadzki, JM pan Jan Szczaniecki, JM pan Zygmunt Twardowski, JM pan Wojciech Kurnatowski, JM pan Piotr Zajączek, JM pan Jan Szułbski, JM pan Jan z Iwanowa Koźmiński, JM pan Adam Lipski, JM pan Jan Zawadzki, JM pan Stanisław ze Smuszewa Mikołajewski, JM pan Piotr Koźmiński, JM pan Wojciech Żychliński, JM pan Marcin Mikołajewski, JM pan Bartłomiej Koźmiński, JM pan Adam Żychliński, JM pan Stanisław Kiełczewski, JM pan Jan Niewiarowski, JM pan Jan Mikołajewski, JM pan Andrzej Koźmiński, JM pan Stanisław Żychliński, JM pan z Przespolewa Stanisław Mikołajewski, JM pan Kierzyński, JM pan Aleksander Mikołajewski, JM pan Jan Radoliński, JM pan Franciszek Mikołajewski, JM pan Aleksander Tomicki, JM pan Stefan Sosiński, JM pan Aleksander Żukowski, [k. 493] JM pan Maciej Olszowski, JM pan Walerian Wilczyński, JM pan Jerzy Kiełczewski, JM pan Jan Dobrzycki, JM pan Chryzostom Dobrzycki, JM pan Jan Dobrzycki młodszy, JM pan Zygmunt Zawadzki, JM pan Andrzej Gądkowski, JM pan Stefan Złotnicki, JM pan Wojciech Bąkowski, JM pan Mikołaj Korzenicki, JM pan Dobrogost Gądkowski, JM pan Kosowski, JM pan Niemierzycki, JM pan Andrzej Krzycki, JM pan Komorowski, JM pan Aleksander Jarochowski, JM pan Wojciech Korzenicki, JM pan Kacper Modlibowski, JM pan Ignacy Bronikowski, JM pan Wierzchaczewski, JM Stanisław Dokowski, JM pan Andrzej Lisiecki, JM pan Rogowski, JM pan Zajączek, JM pan Błaszkowski, JM pan Kromolicki, JM pan Gutowski, JM pan Ciechelski, JM pan Stefan Zakrzewski, JM pan Świętosław Czacki, JM pan Marcin Przystanowski, JM pan Piotr Pawłowski, JM pan Stanisław Zyrzyński, JM pan Adrian Kuczkowski, JM pan Grudzielski, JM pan Wojciech Przespolewski, JM pan Koźliński, JM pan Wojciech Raciborski, JM pan Borecki, JM pan Zaciąski,

\footnotetext{
${ }^{1}$ Jakub Hieronim Rozdrażewski.

2 Władysław Gądkowski.

3 Wawrzyniec Przyborowski.

${ }^{4}$ Krzysztof ze Skrzypny Twardowski.

${ }^{5}$ Stanisław Dobrosielski.
} 
JM pan Piotr Piotrowski, JM pan Kąsinowski, JM pan Szczypierski, JM pan Stefan Pisarski, JM pan Stanisław Rapacki, [k. 493v] JM pan Andrzej Czachórski, JM pan Marcin Malczewski, JM pan Andrzej Wyganowski, JM pan Wojciech Pacynowski, JM pan Bartłomiej Pacynowski, JM pan Wilibrord Pacynowski, JM pan Krzysztof Jasztowski, JM pan Adam Biskupski, JM pan Wojciech i Jan Stolecki, JM pan Stanisław Gogolewski, JM pan Rogalski, JM pan Prokop Kołaczkowski, JM pan Marcin Wtorkowski, JM pan Maksymilian Czacki, JM pan Woliński, JM pan Zaborski na JM pana Stefana miejscu Domiechowskiego.

Władysław z Szczodrzykowa Gądkowski miecznik województwa kaliskiego, porucznik JM pana kasztelana kaliskiego.

\section{Summary}

\section{The 1651 Signature Register of Colonel Jakub Rozdrażewski’s Mass Levy Company from the Kalisz Poviat}

In 1651 , one of the greatest expeditions by the levy in mass was organized. The objective of the mass levy troops was to reach the town of Beresteczko (Berestechko), where one of the heaviest battles would take place during the Bohdan Khmelnytsky uprising begun in 1648. The voivodships (provinces) of Poznan and Kalisz also took part in the expedition. Supervision over its organization in the Kalisz voivodship was the responsibility of the Kalisz castellan Jakub Rozdrażewski, who substituted for the Kalisz voivode (governor) Andrzej Karol Grudziński. When assembling the nobility in the Kalisz poviat (district), the castellan decided to divide them into several groups. Command of one of them was taken by Władysław Gądkowski. The castellan himself also joined the assembled force. During the stopover near Lublin, the muster of Gądkowski's group was held in the field near the town. The signature register listed 109 mass levy members.

\section{Bibliografia}

\section{Źródła drukowane}

Akta sejmikowe województwa betskiego. Lata 1572-1655, oprac. M. Zwierzykowski,

R. Kołodziej, Poznań 2008.

Akta sejmikowe województwa lubelskiego 1572-1632, oprac. H. Gmiterek, Lublin 2016. 
Akta sejmikowe województw poznańskiego i kaliskiego, oprac. W. Dworzaczek, t. 1 (1572-1632), cz.2 (1617-1632), Poznań 1962.

Akta sejmikowe województw poznańskiego i kaliskiego. Lata 1668-1675, oprac. M. Zwierzykowski, R. Kołodziej, A. Kamieński, Poznań 2018.

Akta sejmikowe województw poznańskiego i kaliskiego. Lata 1676-1695, oprac. M. Zwierzykowski, R. Kołodziej, A. Kamieński, Poznań 2019.

Akta sejmikowe województw poznańskiego i kaliskiego. Lata 1696-1732, oprac. M. Zwierzykowski, Poznań 2008.

Akta sejmikowe Ziemi Chełmskiej 1572-1668, oprac. W. Bondyra, H. Gmiterek, J. Ternes, Lublin 2013.

Gmiterek H., Rejestry szlachty ziemi chetmskiej z lat 1669-1672, „Rocznik Chełmski”, t. 2, 1996, s. 327-339.

Goszczyński A., „Szlachty przemyskiej kwiat zgubiony”. Regestr pospolitego ruszenia powiatu przemyskiego pod regimentem skarbnika lwowskiego Zygmunta Przedwojewskiego, [w:] Studia nad staropolska sztuka wojenna, t. 4, red. Z. Hundert, J. J. Sowa, K. Żojdź, Oświęcim 2015, s. 259-275.

Kozyrski R., Popisy (okazowania) szlachty w Rzeczypospolitej w II połowie XVII wieku. Popis Chetmian z 7 sierpnia 1649 roku, „Rocznik Chełmski”, t. 7, 2001, s. 341-358.

Leitgeber S., Spis szlachty powiatu kcyńskiego z 1621 roku, „Genealogia”, t. 5, 1995, S. 141-144.

Okazowania szlachty stężyckiej z lat 1648-1649, wyd. D. Kupisz, „Res Historica”, t. 24, 2007, s. 161-169.

Oświęcim S., Diariusz Stanisława Oświęcima 1643-1651, [w:] Scriptores Rerum Polonicarum, t. 19, wyd. W. Czermak, Kraków 1907.

Popis pospolitego ruszenia szlachty województwa lubelskiego z 1649 roku, wyd. J. Kus, „Region Lubelski”, nr 6 (8), 1994-1996, s. 133-142.

Popis powiatu chęcińskiego z 1621 roku, wyd. Z. Trawicka, „Kieleckie Studia Historyczne”, t. 4,1985 , s. $39-47$.

Popis szlachty ziemi stężyckiej z 1696 roku, wyd. D. Kupisz, „Res Historica”, t. 17, 2004, s. $171-176$.

Rejestr pospolitego ruszenia księstw oświęcimskiego i zatorskiego z 18 października 1621 roku, wyd. J. Pielas, „Res Historica”, t. 42, 2016, s. 353-377.

Rejestr pospolitego ruszenia powiatu sandomierskiego z 1621 r., wyd. J. Pielas, „Studia i Materiały do Historii Wojskowości”, t. 41, 2004, s. 141-169.

Rejestry popisowe szlachty Wielkiego Księstwa Litewskiego z 1621 r., oprac. A. Rachuba, Warszawa 2015. 
Relacje wojenne z pierwszych lat walk polsko-kozackich powstania Bohdana Chmielnickiego okresu „Ogniem i Mieczem” (1648-1651),oprac. M. Nagielski, Warszawa 1999.

Staręgowski B., Rejestr pospolitego ruszenia powiatu poznańskiego z 28 sierpnia 1649 r., „Przegląd Historyczno-Wojskowy”, nr 4 (258), 2016, s. 141-151.

Volumina Constitutionum, t. 4 (1641-1668), vol. 1 (1641-1658), red. S. Grodziski, M. Kwiecień, K. Fokt, Warszawa 2015.

Wierzbicki L., Rejestr pospolitego ruszenia województwa betskiego $z 1669$ r., „Rocznik Lubelski”, t. 42, 2016, s. 229-234.

Źródła i materiały do dziejów szlachty województwa sandomierskiego w XVI-XVIII wieku, t. 1: Rejestry pospolitego ruszenia szlachty sandomierskiej z XVII wieku, oprac. J. Pielas, Kielce 2009.

\section{Literatura}

Hahn K., Pospolite ruszenie wedle uchwat sejmikowych ruskich od XVI do XVIII wieku„”Pamiętnik Historyczno-Prawny”, t. 6, 1928, cz. 4, s. 5-87.

Instrukcja wydawnicza dla źródeł historycznych od XVI do połowy XIX wieku, red. K. Lepszy, Wrocław 1953.

Kłaczewski W., Rozdrażewski Jakub Hieronim, [w:] Polski Słownik Biograficzny, t. 32, Wrocław - Warszawa - Kraków 1989-1991.

Kupisz D., Wyprawy żołnierza łanowego w Koronie w czasach Jana Kazimierza, Warszawa 2018.

Majchrowski J., Wojewoda w dawnej Polsce, Warszawa 2019.

Nagielski M., Pospolite ruszenie szlachty w świetle kampanii zborowskiej i beresteckiej przeciwko Kozakom (1649-1651), [w:] Studia Historyczno-Wojskowe, red. T. Ciesielski, t. 3, 2009, s. 94-112.

Ochmann-Staniszewska S., Sejm Rzeczypospolitej za panowania Jana Kazimierza Wazy. Prawo-doktryna-praktyka, t. 1, Wrocław 2000.

Wierzbicki L., Pospolite ruszenie w Polsce w drugiej połowie XVII wieku.Ostatnie wyprawy $z$ lat 1670-1672, Lublin 2011. 